\title{
Expression profile of active genes in the human pituitary gland
}

\author{
S Tanaka, K Tatsumi, K Okubo', K Itoh ${ }^{1}$, S Kawamoto ${ }^{1}, \mathrm{~K}$ Matsubara ${ }^{1}$ \\ and $\mathbf{N}$ Amino \\ Department of Laboratory Medicine, Graduate School of Medicine, Osaka University, Osaka 565-0871, Japan \\ ${ }^{1}$ Institute for Molecular and Cellular Biology, Osaka University, Osaka 565-0871, Japan \\ (Requests for offprints should be addressed to K Tatsumi; Email: tatsumi@labo.med.osaka-u.ac.jp) \\ (K Matsubara is now at Nara Institute of Science and Technology, Nara 630-0101, Japan)
}

\begin{abstract}
To characterize transcripts abundantly expressed in the human pituitary gland in general as well as to isolate novel transcripts expressed specifically in this gland, we generated an expression profile of the active genes transcribed in it. A total of 1015 randomly collected $3^{\prime}$ expressed sequence tags (ESTs) (gene signatures, GSs) were grouped into 527 GS species. The results showed the relative expression levels of genes in the pituitary gland. The genes comprising more than $1 \%$ of total mRNA were prolactin, growth hormone and chromogranin B genes. When known genes were categorized, the genes for pituitary hormones were the most actively transcribed, followed by the genes for ribosomal proteins, nuclear proteins and secretory granule proteins. Through comparison of this gene expression profile with the BodyMap database containing profiles generated from 63 other human tissues, we obtained 11 genes which appeared to be specifically expressed in the pituitary gland. In addition to the eight known genes, we identified three novel pituitary-specific transcripts which encode putative proteins: pituitary gland specific factor 1a (PGSF1a), PGSF1b and PGSF2. This expression profile method is a novel approach to the isolation of pituitary-specific genes that may have important functions.
\end{abstract}

Journal of Molecular Endocrinology (2002) 28, 33-44

\section{Introduction}

The pituitary gland is composed mainly of endocrine cells producing pituitary hormones. These hormones are stored in the secretory granules and are released by regulated exocytosis. The secretory granules also contain processing enzymes and chromogranins, and fuse with the plasma membrane to release hormones and other contents (Arvan \& Castle 1998).

The unique functions of the pituitary gland are maintained by the pituitary-specific proteins, such as pituitary hormones and transcription factors. Abnormalities in these genes cause both isolated anterior pituitary hormone deficiencies and combined pituitary hormone deficiencies (Phillips et al. 1981, Tatsumi et al. 1992, Cushman \& Camper 2001). Some modification enzymes, such as GalNAc-4-sulfotransferase, are expressed specifically in the pituitary gland (Okuda et al. 2000), while others, such as prohormone convertase (PC) 1/3, PC2, carboxypeptidase E (CPE) and neuroendocrine protein 7B2 (Iguchi et al. 1984) are also expressed in the pancreas and neural tissues (Gorr et al. 2001). Abnormalities in CPE and 7B2 cause adrenocorticotropin (ACTH) to be secreted in an unregulated manner (Gorr et al. 2001). Autoantibodies against tissue-specific proteins have proven to be useful markers for autoimmune diseases. Although pituitary-specific autoantibodies for lymphocytic hypophysitis have been reported, the corresponding autoantigens have not been identified (Crock 1998, Nishiki et al. 2001).

In order to clarify the molecular basis of the tissue specificity of the pituitary gland and to resolve the mechanism of pituitary diseases, isolation of pituitary-specific transcripts is important. In an attempt to identify the molecules expressed specifically in the human pituitary gland, we used a method called gene expression profiling 
(Okubo et al. 1992). This method involves the construction of a $3^{\prime}$-directed cDNA library that faithfully represents the original composition of the mRNA species, and random sequencing of the cDNA clones to obtain $3^{\prime}$ expressed sequence tags (ESTs), each consisting of short nucleotide sequences just upstream of the poly(A) tail to the adjacent GATC (MboI site). These 3' ESTs are called gene signatures (GSs), since they are unique to the individual genes (Okubo et al. 1992). Expressed genes are identified by their GS species, and the relative abundance of each transcript can be estimated by the frequency of the corresponding GS species in the library. The resulting gene expression profile thus describes quantitative aspects of the genes active in the human pituitary gland. Similar gene expression profiles based on 64 human tissues make up the molecular anatomy database known as the BodyMap database (Hishiki et al. 2000, Kawamoto et al. 2000). By comparing the expression profiles obtained from various tissues in the BodyMap database, many tissue-specific genes and a disease causing gene have been identified (Okubo et al. 1995, Kita et al. 1996, Nishida et al. 1996, Yokoyama et al. 1996, Maeda et al. 1997, Nishida et al. 1997, Shimizu-Matsumoto et al. 1997, Itoh et al. 1998). Thus, this method is an effective alternative method for identifying novel genes in addition to other methods, such as functional cloning, similarity cloning, positional cloning and traditional subtraction cloning.

In the present study, we report a list of genes actively expressed in the human pituitary gland; prolactin (PRL) was found to be the most abundantly expressed gene in this tissue sample. By comparing the gene expression profile of the human pituitary gland with the BodyMap database, we identified three novel transcripts that are expressed specifically in the human pituitary gland.

\section{Materials and methods}

\section{Construction of the 3 -directed library and sequencing analysis}

Poly(A) RNA from the human pituitary gland, obtained from 21 individuals aged 16 to 70 years, was purchased from Clontech (Palo Alto, CA, USA). Construction of the $3^{\prime}$-directed cDNA libraries and transformation into $E$. coli were performed as previously described (Okubo et al.
1992). Briefly, cDNA was synthesized using a pUC19 based vector-primer, which was digested by $M b o I$, and circularized and transformed into E. coli. The insert cDNAs of the randomly isolated transformants were prepared by PCR amplification for the sequence templates. The amplified products were sequenced directly using a dye primer cycle sequencing kit (Perkin-Elmer, Norwalk, CT, USA) and an ABI PRISM 373 Genetic Analyzer (Perkin-Elmer).

The resulting sequences, referred to as GSs, were compared with each other using BLAST (Altschul et al. 1994), and clustered. From each cluster, one representative GS was selected and compared with representative sequences from the previously generated clusters. A GS number was assigned to each independent cluster. The representative sequences for the GS clusters (GS species) were searched against the DDBJ/GenBank/EMBL database using BLAST (Altschul et al. 1994).

\section{In silico RNA experiments}

Frequencies of each GS were compared with those in the BodyMap database. Specific expression of each GS species in the human pituitary gland was described as a pituitary TS ratio according to the following formula:

pituitary TS ratio

$$
=\frac{\frac{(\text { frequency of a GS species in the pituitary gland) }}{\text { (total number of GSs in the pituitary gland) }}}{\frac{\text { (frequency of a GS species in the whole BodyMap database) }}{\text { (total number of GSS in the whole BodyMap database) }}}
$$

\section{Screening of the cDNA library}

The human pituitary gland cDNA library, which was constructed with a ZAP-cDNA Synthesis kit (Stratagene, La Jolla, CA, USA) using a Uni-ZAP $\mathrm{XR}$ vector, was screened using standard techniques. The alkaline phosphatase-labeled probes for the GS sequences were synthesized by an Alphos direct system (Amersham Pharmacia, Arlington Heights, IL, USA). After the phage plaques were transferred to a nylon membrane (Hybond N+, Amersham Pharmacia) according to the standard alkali transfer method, the membranes were baked at $80^{\circ} \mathrm{C}$ for $2 \mathrm{~h}$. Then the membranes were hybridized with each probe at 
Table 1 Nucleotide sequence of primers used for expression analysis

\section{Sense primer}

GS

GS9544 (PGSF1)

GS9589 (PGSF2) 3'

GS9589 (PGSF2) 5'

GS9573 (KIAA0512)
GACAGGACGGCGAAGTTTGA

AGGACTTATATGCCAGGCAC

CGCTCTAGAACTAGTGGATC

TGCTGAGTTCAGGTTAGAGGCC
Antisense primer

TCCTTATTGCCTCACCATTTCC

TGTTATTTTTATGTGTGGAA

TTTGTGTCTTATCCTTCAGCAGCAG GTTACTGCTTTTCCACTTGCTC

PGSF, pituitary gland specific factor.

Table 2 Cellular lozalization of GSs in the expression profile of the pituitary gland

\section{Localization}

I. Known genes

Extracellular proteins

Secretory proteins

Pituitary hormones

Other secretory proteins

Matrix proteins

Plasma membrane proteins

Intracellular proteins

Secretory granule proteins

ER-Golgi proteins

Nuclear proteins

Mitochondrial proteins

Lysosomal proteins

Cytoplasmic proteins

Ribosomal proteins

Signal transducers

Cytoskeletal proteins Others

Uncharacterized

II. Novel genes

Total

\section{GS species}

263

16

12

5

7

4

12

172

$(9-10)^{\mathrm{a}}$

18

32

17

15

80

50

$(15-16)^{a}$

8

6

63

264

527

\section{GSs}

658

238

234

219

14

5

20

301

$(25-34)^{a}$

21

49

23

17

158

100

$(17-26)^{\mathrm{a}}$

17

15

98

357

1015

\section{Frequency (\%)}

$64 \cdot 8$

$23 \cdot 4$

$23 \cdot 1$

$21 \cdot 6$

1.4

0.5

2.0

29.8

$(2 \cdot 5-3 \cdot 4)^{\mathrm{a}}$

$2 \cdot 1$

$4 \cdot 8$

$2 \cdot 3$

1.7

$15 \cdot 6$

9.9

$(1 \cdot 7-2 \cdot 6)^{a}$

1.7

1.5

9.7

$35 \cdot 2$

$100 \cdot 0$

Sequences of the 1015 independent clones from the 3'-directed library were grouped into 527 GS species according to the sequence identity. These GS species were divided into those that matched known genes and those that did not. Species in the former group were categorized according to the cellular localization of their products and then subcategorized. The numbers in parenthesis show the numbers of GS species and the number of GSs in subcategories. ${ }^{a}$ Variation caused by GNAS1 gene corresponding to GS1007 (see Table 3). ER, endoplasmic reticulum.

$55{ }^{\circ} \mathrm{C}$ overnight. After hybridization, the membranes were washed with a primary wash buffer (2 M urea, $0 \cdot 1 \%$ SDS, $50 \mathrm{mM}$ Na phosphate $\mathrm{pH}$ $7 \cdot 0,150 \mathrm{mM} \mathrm{NaCl}, 1 \mathrm{mM} \mathrm{MgCl}_{2}$, with $0 \cdot 2 \%$ blocking reagent) at $55{ }^{\circ} \mathrm{C}$ for 10 min twice and then washed with a secondary wash buffer $(50 \mathrm{mM}$ Tris base, $100 \mathrm{mM} \mathrm{NaCl}, 2 \mathrm{mM} \mathrm{MgCl}_{2}$ ) at room temperature for $5 \mathrm{~min}$ twice. The positive signals were detected with CDP-Star detection reagent (Amersham Pharmacia) by exposure to diagnostic film (RX-U, Fuji Film, Tokyo, Japan) with an intensifier screen at room temperature for $1 \mathrm{~h}$ or more. Double-strand plasmid DNAs of the positive clones were rescued by following the manufacturer's procedure. DNA sequencing was performed with an ABI PRISM 373 Genetic Analyzer (Perkin-Elmer).

\section{Rapid amplification of $5^{\prime}$-cDNA ends (5'-RACE)}

A Marathon cDNA Amplification kit (Clontech) was used to determine the $5^{\prime}$ ends of GS9544, 


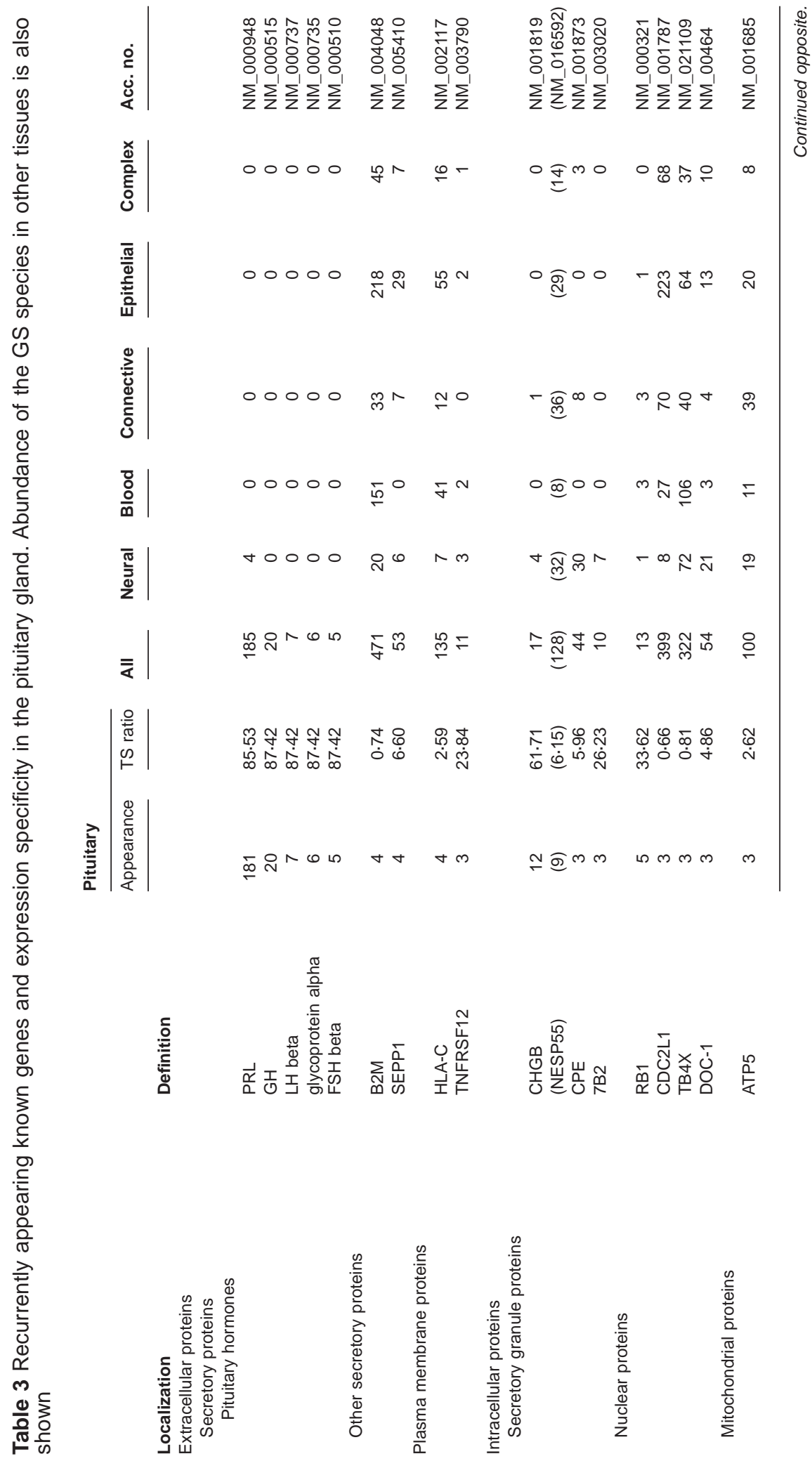




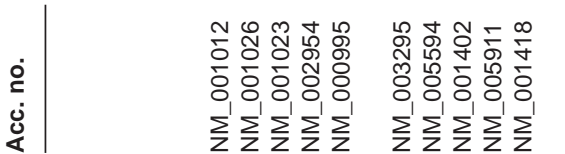

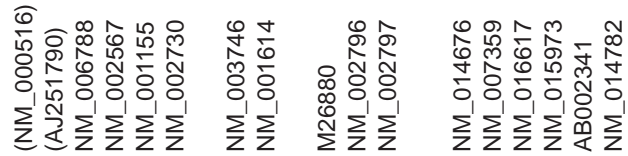

爻|

กิㅇํํํํำ

ํํำ

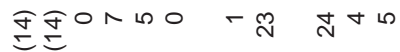

ON NOOO

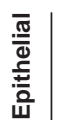

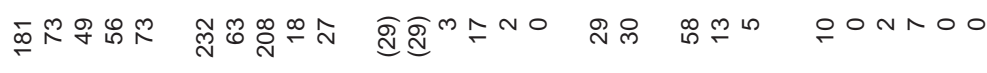

总

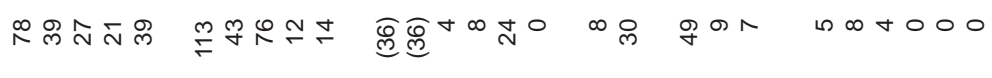

$\frac{\mathrm{o}}{\mathrm{m}}$

œ

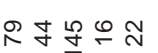

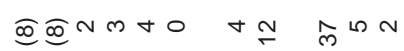

$r+n-00$

䨠

$N \infty-\circ m$

बสำ

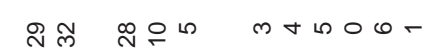

$\bar{\varepsilon}$

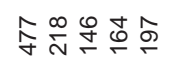

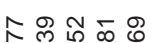

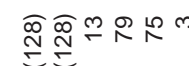

임 웜소

$\stackrel{\infty}{\sim} \stackrel{\infty}{\sim} \mp \sigma+$

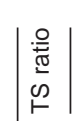

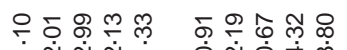

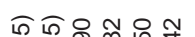

\section{$\bar{\infty}$}

뇨

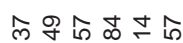

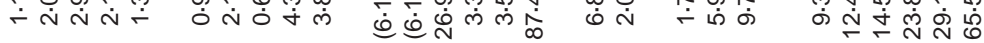

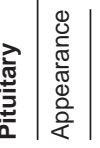

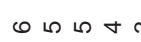

00 เ 6

बढ्वणmलm

$0 m+\infty m$

लாलாल

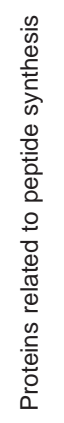

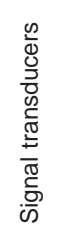

$$
\begin{aligned}
& \frac{0}{\frac{0}{0}} \\
& \frac{0}{0} \\
& \frac{0}{0} \\
& \frac{\pi}{0} \\
& \frac{0}{0} \\
& \frac{10}{0} \\
& \frac{0}{0} \\
& 0
\end{aligned}
$$
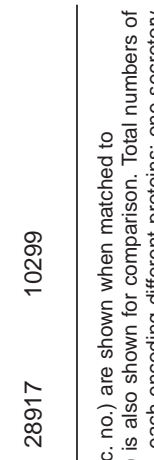

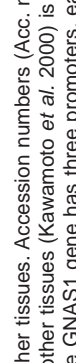

芯

$\widetilde{N}$
$\infty$
$\infty$
$\infty$

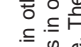

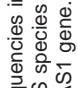

产它尔

可

亦这完

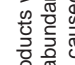

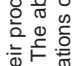

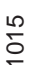

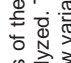

을 듕

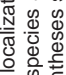

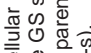

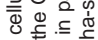

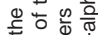

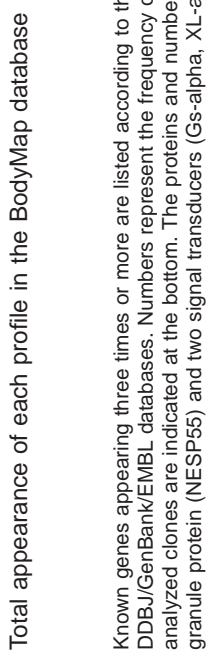


Table 4 GS species expressed uniquely in the pituitary gland

\begin{tabular}{|c|c|c|c|}
\hline & & $\begin{array}{l}\text { Appearance in } \\
\text { the pituitary }\end{array}$ & $\begin{array}{l}\text { Expression } \\
\text { analysis }\end{array}$ \\
\hline GS species & Definition & & \\
\hline $9703^{\circ}$ & PRL & 181 & \\
\hline 9496 & $\mathrm{GH}$ & 20 & \\
\hline 7687 & CHGB & 12 & \\
\hline 9512 & glycoprotein alpha & 7 & \\
\hline 9535 & LH beta & 6 & \\
\hline \multirow[t]{2}{*}{9544} & PGSF1a ${ }^{a}$ & 6 & ps \\
\hline & PGSF1b ${ }^{a}$ & & ps \\
\hline 9504 & FSH beta & 5 & \\
\hline 9651 & & 4 & \\
\hline 9589 & PGSF2 $^{\mathrm{a}}$ & 3 & ps \\
\hline 9606 & PRKACA & 3 & \\
\hline 9573 & KIAA0512 & 3 & ppd \\
\hline
\end{tabular}

The GS species listed appeared frequently and specifically in the pituitary gland. Numbers represent the frequencies of the GS species analyzed. ${ }^{2}$ Definitions identified in this study; ps: pituitary-specific; ppd: pituitary-predominant.

GS9589 and GS9573 according to the manufacturer's protocol. One microgram of poly(A) RNA from the human pituitary gland was reverse transcribed using a ReverTraAce (Toyobo, Osaka, Japan) with random hexamers. Double strand DNA synthesis and adapter (5'-CTAATACGA CTCACTATAGGGCTCGAGGGGCGGCGCG GGCAGGT-3', 3'-H2N-CGCGTCGA-PO4-5') ligation were carried out according to the manufacturer's protocol (Clontech). The PCR was carried out with an adapter primer 1 (AP1, 5'-CGATCGTAATACGACTCACTATAGGGC$\left.3^{\prime}\right)$ and gene specific primers for GS9544 (5'CTGAGACGACGCGTCGTGGGAGGCA-3'), GS9589 (5'-TGTCTGCTTCGAGTAGCAGGAC CGGTAAA-3') and GS9573 (5'-AGACAGACG CTCGAAAGATTCA-3'). The PGR products were sequenced with $\mathrm{AP} 1$ or gene specific primers.

\section{Northern hybridization}

Poly(A) RNA from the human pituitary gland and liver (Clontech) were fractionated on a formaldehyde-agarose gel and transferred to a Hybond $\mathrm{N}+$ membrane according to the manufacturer's recommendation. This membrane or Northern LIGHT Human Multiple mRNA Blot I (Life Technologies, Gaithersburg, MD, USA) containing human heart, brain, liver, pancreas, skeletal muscle and lung mRNA, was hybridized with the probes based on the putative open reading frame (ORF) region of the screened cDNA clones labeled with the enhanced chemiluminescence (ECL) direct system (Amersham Pharmacia). The membranes were hybridized and washed according to the protocol provided with the ECL direct system. The membranes were exposed to RX-U diagnostic film with an intensifier screen at room temperature for $1 \mathrm{~h}$ or more. The probes were obtained by PGR using the primers listed in Table 1.

\section{Results and discussion}

\section{Gene expression profile of the human pituitary gland}

To understand the molecular basis of the synthesis and secretion of pituitary hormones, we constructed a gene expression profile of the human pituitary gland. This profile shows the relative activities of the genes in maintaining the tissue specificity. From the 3 '-directed cDNA library of the human pituitary gland, 1015 GSs were obtained (Table 2). These sequences were compared and found to make up 527 independent GS species. Among the 527 GS species, 263 GS species represented by $658 \mathrm{GSs}$ were derived from genes registered in the DDBJ/GenBank/EMBL database and 264 GS species represented by 357 GSs were derived from novel genes.

In Table 3, the frequencies of the recurrently appearing genes in the human pituitary gland are 

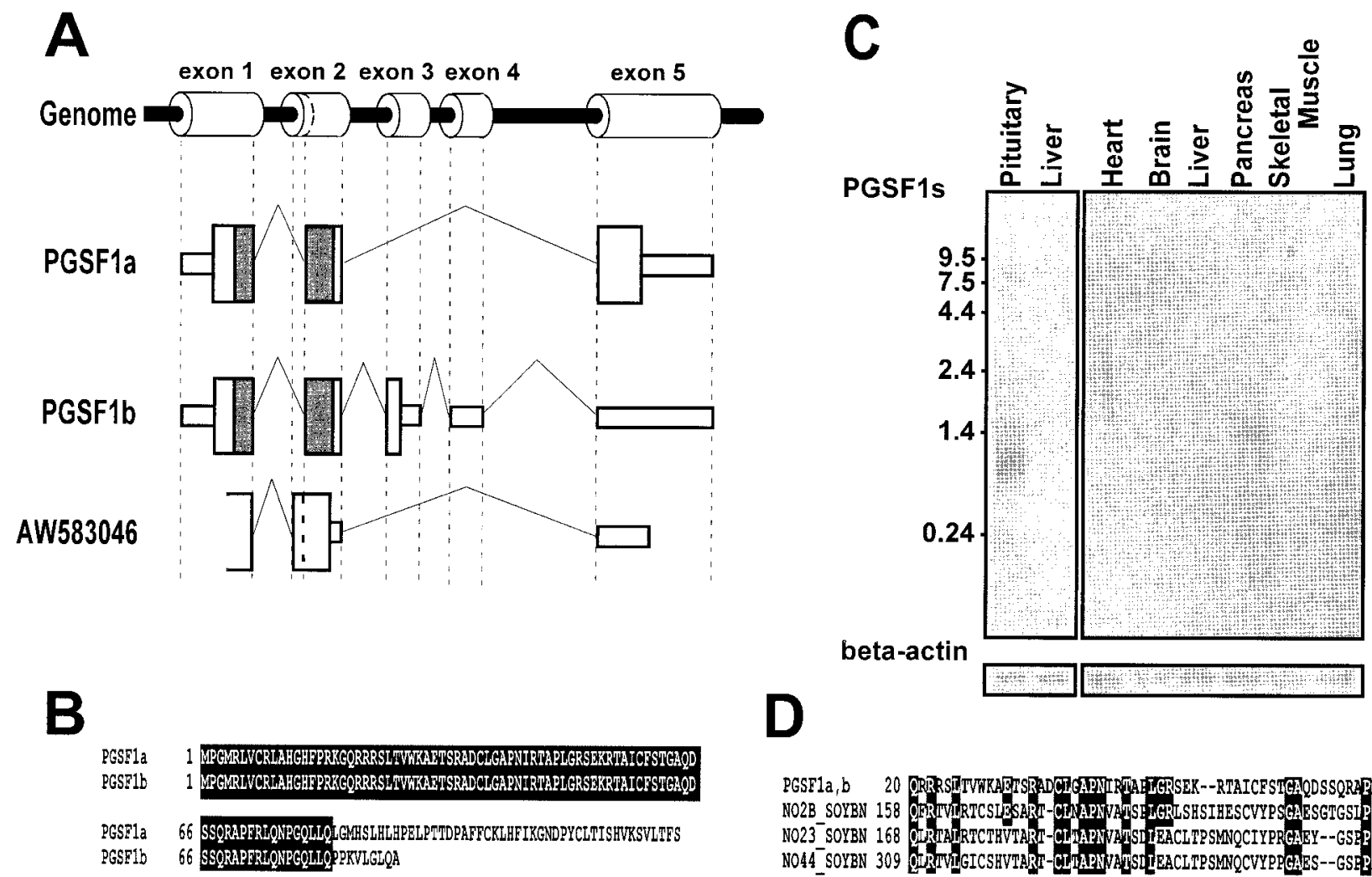

Figure 1 Expression and structure of PGSF1s. (A) Schematic structure of PGSF1s. (Top) Structure of the PGSF1 gene. (Below) cDNA structure of PGSF1s. The tall and short rectangles in the cDNA structure represent the putative open reading frame (ORF) and non-coding sequence respectively. Shaded rectangles indicate the conserved region with soybean nodulin families (see D). AW583046 is alternatively spliced at exon 2 and has a 53-bp insertion causing a frame shift in the putative ORF. (B) Amino acid sequence alignment of PGSF1s. (C) Multi-tissue Northern hybridization for PGSF1s and beta-actin. (D) Amino acid sequence alignment of PGSF1s and soybean nodulin families. The amino acids identical with PGSF1s are highlighted. NO2B_SOYBN: soybean nodulin 26B;

NO23_SOYBN: soybean nodulin 23; NO44_SOYBN: soybean nodulin $\overline{44}$.

compared with those in 63 other tissues in the BodyMap database, and their tissue specificities for the pituitary gland are indicated by pituitary TS ratios. To characterize the active genes in the human pituitary gland, we categorized these GS species mainly according to their cellular localization with subclassification, together with their frequencies in the pituitary gland, as summarized in Table 2. The PRL gene was most actively expressed, followed by the growth hormone $(\mathrm{GH})$ gene. All of the genes for pituitary hormones listed (PRL, GH, luteinizing hormone (LH) beta, glycoprotein alpha, follicle-stimulating hormone (FSH) beta) were expressed specifically in the pituitary gland and were most frequently expressed in the human pituitary gland $(23.4 \%)$ (Tables 2 and 3).
The third most abundant transcript was that for the chromogranin B (CHGB) gene. CHGB is a secretory granule protein related to the regulated secretory pathway. Two other secretory granule protein genes, CPE and 7B2, were predominantly expressed in the pituitary gland and neural tissues concordant with their known characters. These secretory granule protein genes were included in the fourth most frequently expressed group $(2 \cdot 3-3 \cdot 4 \%)$ (Tables 2 and 3 ).

With respect to genes specific to both the pituitary gland and neural tissues, all the previously well characterized genes are either pituitary hormones or secretory granule proteins, with the exception of the cAMP-dependent catalytic alpha subunit (PRKACA); therefore, other littlecharacterized genes expressed predominantly in 

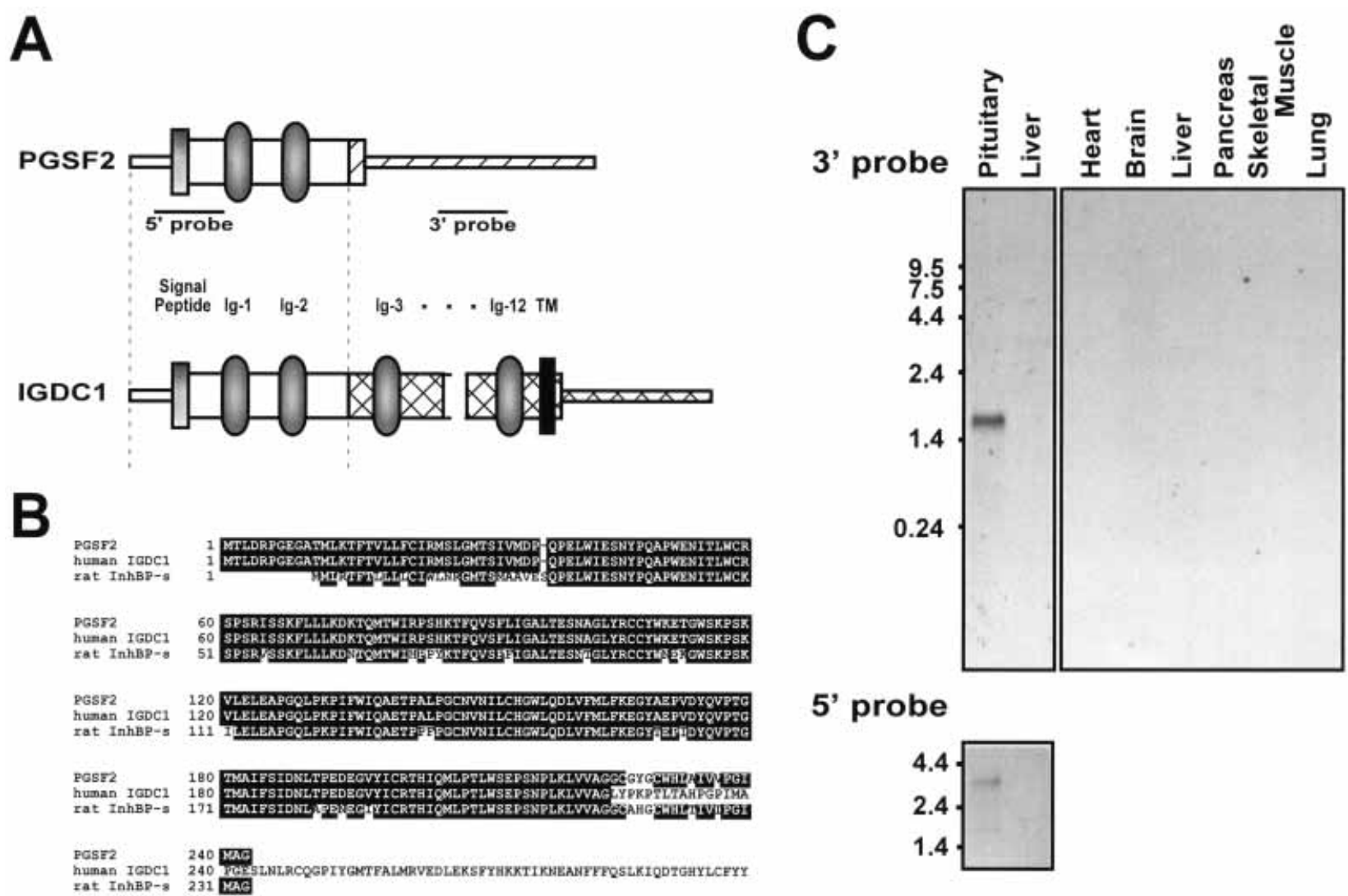

5' probe

Figure 2 Expression and structure of PGSF2. (A) Schematic structure of PGSF2 and IGDC1. The tall and short rectangles represent the putative ORF and non-coding sequence respectively. Each hatched pattern indicates a different nucleotide sequence. Signal peptide, Ig-like domains, transmembrane domains (TMs), and probes used for the Northern hybridization are indicated. (B) Amino acid sequence alignment of PGSF2, IGDC1 and InhBP-s. The identical amino acids are highlighted. (C) Multi-tissue Northern hybridization with the 3 ' probe unique to PGSF2 and the $5^{\prime}$ probe.

the pituitary gland and neural tissues, such as KIAA0343 and KIAA0512, may well be related to the regulated secretory pathway.

The fourth most abundant transcript was that for the GNAS1 gene. The gene encodes three proteins, Gs-alpha, an extra large G protein (XL-alpha-s) and NESP55, transcribed from three different promoters (Kozasa et al. 1988, Kehlenbach et al. 1994, Ischia et al. 1997). Activities for Gs-alpha have been detected in various tissues, although expressions of XL-alpha-s and NESP55 are limited to neuroendocrine tissues, and inactive or active mutations cause endocrinological abnormalities, e.g. Albright hereditary osteodystrophy (Patten et al. 1990, Weinstein et al. 1992) and McCune-Albright syndrome (Schwindinger et al. 1992). In agreement with the activities for Gs-alpha, their expressions as a whole were not limited to the pituitary gland and neural tissues in the BodyMap database (Table 3).

Most of the other recurrently appearing genes were not expressed specifically in the pituitary gland or tissue groups, and thus were considered housekeeping genes. Ribosomal protein genes $(9.9 \%)$ and nuclear protein genes $(4 \cdot 8 \%)$ were frequently expressed. Some of these genes may serve as better internal references for comparing expression levels among tissues, since beta-actin and glyceraldehyde-3-phosphate dehydrogenase, two commonly used references, were expressed infrequently and unequally among tissues in the BodyMap database.

$\mathrm{Hu}$ et al. (2000) also recently reported an expression profile of the human pituitary gland. Their profile was based on seven thousand $5^{\prime}$ ESTs from cDNAs, one third of which contained the first 


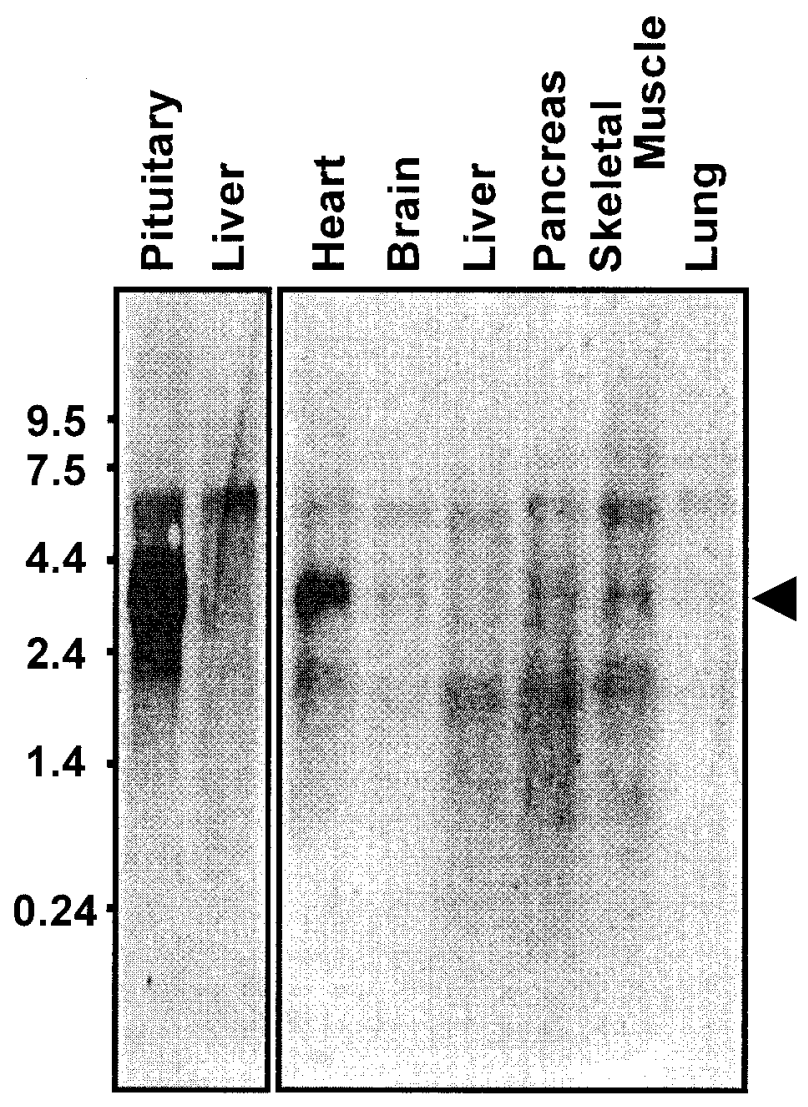

Figure 3 Expression of KIAA0512. Multi-tissue Northern hybridization for KIAA0512.

ATG. They compared it with expression profiles of the hypothalamus and adrenal gland. In agreement with our observation, GH and PRL were expressed in over $1 \%$ of the total ESTs analyzed. Other recurrently appearing, known genes in Table 3 were also observed in their profile, but not the genes SEPP1, NACA, EIF4G2, TNFRSF12, PBP, ANXA6, PRKACA or several of the uncharacterized genes, such as Pumilio homolog 1, MLN51, KIAA0343 and KIAA0512. Among the pituitary hormones, thyrotropin (TSH) beta and proopiomelanocortin (POMG) did not appear in our profile, PRL was 10 times more abundant in our profile, and FSH beta did not appear in their profile. To assess the qualities of these profiles, comparisons of well-characterized pituitary hormones would be of use.

Because TSH beta cDNA lacks an MboI site (Tatsumi et al. 1988), it does not appear as a GS. The extremely high expression of PRL in our profile was not due to specific endocrinological conditions for the following reason. The high level of PRL in our samples is unlikely to be caused by overexpression of this mRNA in one or two of the subjects, even if suffering from a prolactinoma or another metabolic disturbance. The pituitary mRNA used in our study was derived from 21 individuals, each contributing approximately the same amount of RNA. Hence high expression of PRL in a small number of individuals would be diluted by the RNA from the other individuals in the total sample. The absence of POMC may reflect a low content of ACTH in the anterior pituitary gland (Matsuyama et al. 1971, Moldow \& Yalow 1978, Ishikawa et al. 1987). In agreement with our profile, previously measured expression levels for FSH beta and LH beta showed similar quantitative mRNA measurements (Dalkin et al. 1989).

Our method has two major advantages over other gene expression profiling methods. First, compared with the gene expression profiling methods obtained from a single tissue or from several tissues, the BodyMap database of 63 other human tissues is currently available, and comparison of the pituitary-gland expression profile composed using the same method as used for the BodyMap database should readily reveal candidates for tissue-specific transcripts. Secondly, the length of most GSs was under $1 \mathrm{~kb}$ and over $30 \mathrm{bp}$, allowing us to avoid artifacts in library construction while providing probes for further analyses. Indeed, this method has been successful in isolating tissue-specific genes in various other tissues (Okubo et al. 1995, Kita et al. 1996, Nishida et al. 1996, Yokoyama et al. 1996, Maeda et al. 1997, Shimizu-Matsumoto et al. 1997, Itoh et al. 1998). We therefore concluded that our profile is reliable, although verification through future analyses of other gene expression profiles obtained from other methods or other primates will be needed.

\section{Human pituitary gland-specific gene expression profile}

To identify genes that may play important roles in the pituitary gland, we selected GS species expressed recurrently and specifically in the pituitary gland (Table 4). Eight of the $11 \mathrm{GS}$ species were from known genes. Five of these (PRL, GH, LH beta, glycoprotein alpha and FSH beta) were anterior pituitary hormones, two (CHGB and PRKACA) were specific to the endocrine tissues, 
and the remaining one (KIAA0512) has not been characterized.

By screening a human pituitary gland cDNA library with the GS sequences, we obtained cDNA clones for GS9544, GS9589, and GS9573 (Table 4). GS9651 represented a unique sequence in the human genome draft sequence (International Human Genome Sequencing Consortium 2001, Venter et al. 2001), but screenings for cDNA clones were unsuccessful. Northern hybridization showed that GS9544 and GS9589 were pituitary-specific and GS9573 (KIAA0512) was pituitary-predominant.

\section{Characterization of novel pituitary-specific transcripts}

For GS9544, two splice variants of $0.7 \mathrm{~kb}$ and $0.9 \mathrm{~kb}$ were isolated from the human pituitary cDNA library. They encoded two putative proteins, pituitary gland specific factor la (PGSFla) of 128 amino acids (aa) and PGSFlb of 91 aa (Fig. 1A,B). A BLAST search against the human genome draft sequence localized PGSF1s to chromosome 19 (accession no. (ACC\#) NT_011255) (International Human Genome Sequencing Consortium 2001). In the EST database, a short partial human cDNA from the islets of Langerhans cDNA library represented another splice variant (ACC\# AW583046) (Fig. 1A). The cDNA probe for the two PGSF1s (PGSFla and PGSF1b) hybridized strongly with pituitary transcripts of approximately $1 \mathrm{~kb}$ and weakly with pancreas transcripts of approximately $1.4 \mathrm{~kb}$ by multi-tissue Northern hybridization (Fig. 1G). These are presumably endocrine-specific transcripts expressed most specifically in the pituitary gland. They may be proteins related to secretory granules, one of the most abundant members in the gene expression profile of the human pituitary gland. PGSF1s have a homology of $33 \%$ within 51 aa with the soybean nodulin 26B-carboxy terminal domain (Jacobs et al. 1987) (Fig. 1D). Nodulins are proteins associated with the peribacteroid membrane of soybean root nodules, and the carboxyl terminal domain is in the cytoplasmic fraction of the nodule. Although the functions of this domain have not been identified (Panter et al. 2000), the fact that this domain is conserved between humans and soybeans may well indicate that it has a novel function.
Full-length cDNA for GS9589 was 2 kb in length and encoded a putative protein, PGSF2, of 242 aa (Fig. 2A). A BLAST search revealed that the 5' $0.8 \mathrm{~kb}$ of this cDNA was identical with exons $1-5$ of the immunoglobulin (Ig)-like domain containing 1 (IGDC1) (Frattini et al. 1998) and was a human counterpart for the recently identified rat inhibin binding protein short isoform (InhBP-S) (Bernard \& Woodruff 2001) (Fig. 2B). The IGDCl protein consists of an N-terminal signal peptide, twelve Ig-like domains and a C-terminal transmembrane domain (Fig. 2A). PGSF2 is a splice variant of IGDC1, and is probably secreted. A $3^{\prime}$ probe unique to PGSF2 hybridized with pituitary-specific transcripts of approximately $2 \mathrm{~kb}$ by multi-tissue Northern hybridization (Fig. 2C). While the 3' probe hybridized with pituitary-specific transcripts, a $5^{\prime}$ probe hybridized with a $2 \mathrm{~kb}$ band and a longer band encoding PGSF2 and IGDC1 respectively (Fig. 2G). The InhBP long isoform (InhBP-L), an ortholog of IGDC1, was identified as an inhibin A-specific receptor (Bernard \& Woodruff 2001). Because transcripts for InhBP-S and InhBP-L have been detected specifically in the rat pituitary gland and testis (Bernard \& Woodruff 2001) and transcripts for IGDCl have been detected in the human testis and prostate (Frattini et al. 1998), both PGSF2/InhBP-S and IGDC1/ InhBP-L are expressed specifically in tissues with secretory granules in humans and rats. A BLAST search against the human genome draft sequence localized PGSF2 to the chromosome X q25-26.2 region. The gene for $\mathrm{X}$-linked recessive panhypopituitary dwarfism lies in this region (LagerstromFermer et al. 1997). If PGSF2 is responsible for this disease, it would be involved in the development or functions of the pituitary gland.

Full-length cDNA for GS9573 matched the cDNA encoding KIAA0512, except that the former cDNA had an insertion of $44 \mathrm{bp}$ at the $5^{\prime}$ noncoding region. The KIAA0512 protein is a putative protein of 632 aa, possesses an armadillo/ beta-catenin-like repeat motif, and has homology of $61 \%$ within 307 aa with a putative protein (ACC\# AF211175). By multi-tissue Northern hybridization, KIAA0512 was expressed as $3 \cdot 2 \mathrm{~kb}$ and $4.5 \mathrm{~kb}$ transcripts in all tissues examined, but at different levels, with the highest expression occurring in the pituitary gland and heart (Fig. 3). Because the putative protein (AGC\# AF211175) bound to non-erythroid alpha-spectrin in vivo (a 
note in the GenBank database) and the spectrin families are structural proteins that are located adjacent to membrane or Golgi body, the KIAA0512 protein may form a complex with spectrin and other spectrin binding proteins (for example, ankylin, actin or band $4 \cdot 1$ ), and may act as a transport component for the vesicles.

Consequently, the expression profile of the human pituitary gland and its comparison with the expression profiles of other tissues provided an alternative way of isolating genes expressed specifically in the human pituitary gland. Expanding the numbers of GSs will further enable us to identify less abundant pituitary-specific genes. In the present study, we obtained three transcripts from two novel GSs expressed specifically in the human pituitary gland. With the help of recently developed oligonucleotide-based, PCR-mediated multi-tissue quantitative expression analyses (Heid et al. 1996, Kato 1997, Hall et al. 1998, Kawamoto et al. 1999), which are more rapid and specific than Northern hybridization, we will be able to select pituitary-specific genes more easily in the future. These genes will serve as promising candidates for pituitary diseases, such as congenital pituitary abnormalities and autoantigens for lymphocytic hypophysitis.

\section{Acknowledgements}

We thank Dr M Kimura and Dr T Takano for their helpful discussions. This work was supported in part by grants from the Ministry of Education, Culture, Sports, Science and Technology of Japan, the Ministry of Health, Labour and Welfare of Japan, the Foundation for Growth Science in Japan, and the Kato Memorial Trust for Nanbyo Research.

\section{References}

Altschul SF, Boguski MS, Gish W \& Wootton JC 1994 Issues in searching molecular sequence databases. Nature Genetics 6 119-129.

Arvan P \& Castle D 1998 Sorting and storage during secretory granule biogenesis: looking backward and looking forward. Biochemical fournal 332 593-610.

Bernard DJ \& Woodruff TK 2001 Inhibin binding protein in rats: alternative transcripts and regulation in the pituitary across the estrous cycle. Molecular Endocrinology 15 654-667.

Crock PA 1998 Cytosolic autoantigens in lymphocytic hypophysitis. Fournal of Clinical Endocrinology and Metabolism 83 609-618.

Cushman LJ \& Camper SA 2001 Molecular basis of pituitary dysfunction in mouse and human. Mammalian Genome 12 485-494.
Dalkin AC, Haisenleder DJ, Ortolano GA, Ellis TR \& Marshall JC 1989 The frequency of gonadotropin-releasing-hormone stimulation differentially regulates gonadotropin subunit messenger ribonucleic acid expression. Endocrinology 125 917-924.

Frattini A, Faranda S, Redolfi E, Allavena P \& Vezzoni P 1998 Identification and genomic organization of a gene coding for a new member of the cell adhesion molecule family mapping to Xq25. Gene 214 1-6.

Gorr SU, Jain RK, Kuehn U, Joyce PB \& Cowley DJ 2001 Comparative sorting of neuroendocrine secretory proteins: a search for common ground in a mosaic of sorting models and mechanisms. Molecular and Cellular Endocrinology 172 1-6.

Hall LL, Bicknell GR, Primrose L, Pringle JH, Shaw JA \& Furness PN 1998 Reproducibility in the quantification of mRNA levels by RT-PCR-ELISA and RT competitive-PCR-ELISA. Biotechniques 24 652-658.

Heid CA, Stevens J, Livak KJ \& Williams PM 1996 Real time quantitative PCR. Genome Research 6 986-994.

Hishiki T, Kawamoto S, Morishita S \& Okubo K 2000 BodyMap: a human and mouse gene expression database. Nucleic Acids Research 28 136-138.

Hu RM, Han ZG, Song HD, Peng YD, Huang QH, Ren SX, Gu YJ, Huang CH, Li YB, Jiang CL et al. 2000 Gene expression profiling in the human hypothalamus-pituitary-adrenal axis and full-length cDNA cloning. PNAS 97 9543-9548.

Iguchi H, Chan JS, Seidah NG \& Chretien M 1984 Tissue distribution and molecular forms of a novel pituitary protein in the rat. Neuroendocrinology 39 453-458.

International Human Genome Sequencing Consortium 2001 Initial sequencing and analysis of the human genome. Nature $\mathbf{4 0 9}$ 860-921.

Ischia R, Lovisetti-Scamihorn P, Hogue-Angeletti R, Wolkersdorfer M, Winkler H \& Fischer-Colbrie R 1997 Molecular cloning and characterization of NESP55, a novel chromogranin-like precursor of a peptide with 5-HT1B receptor antagonist activity. Fournal of Biological Chemistry 272 11657-11662.

Ishikawa J, Fuse Y \& Wakabayashi K 1987 Choice of extraction procedure for estimation of anterior pituitary hormone content. Endocrinologia Faponica 34 755-767.

Itoh K, Okubo K, Utiyama H, Hirano T, Yoshii J \& Matsubara K 1998 Expression profile of active genes in granulocytes. Blood $\mathbf{9 2}$ $1432-1441$.

Jacobs FA, Zhang M, Fortin MG \& Verma DP 1987 Several nodulins of soybean share structural domains but differ in their subcellular locations. Nucleic Acids Research 15 1271-1280.

Kato K 1997 Adaptor-tagged competitive PCR: a novel method for measuring relative gene expression. Nucleic Acids Research $\mathbf{2 5}$ $4694-4696$.

Kawamoto S, Ohnishi T, Kita H, Chisaka O \& Okubo K 1999 Expression profiling by iAFLP: a PCR-based method for genome-wide gene expression profiling. Genome Research $\mathbf{9}$ $1305-1312$.

Kawamoto S, Yoshii J, Mizuno K, Ito K, Miyamoto Y, Ohnishi T, Matoba R, Hori N, Matsumoto Y, Okumura T et al. 2000 BodyMap: a collection of $3^{\prime}$ ESTs for analysis of human gene expression information. Genome Research 10 1817-1827.

Kehlenbach RH, Matthey J \& Huttner WB 1994 XL alpha s is a new type of G protein. Nature $372804-809$.

Kita H, Okubo K \& Matsubara K 1996 An expression profile of active genes in cultured human keratinocytes. DNA Research 3 1-7.

Kozasa T, Itoh H, Tsukamoto T \& Kaziro Y 1988 Isolation and characterization of the human Gs alpha gene. PNAS $\mathbf{8 5}$ 2081-2085.

Lagerstrom-Fermer M, Sundvall M, Johnsen E, Warne GL, Forrest SM, Zajac JD, Rickards A, Ravine D, Landegren U \& Pettersson U 1997 X-linked recessive panhypopituitarism associated with a 
regional duplication in Xq25-q26. American foumal of Human Genetics 60 910-916.

Maeda K, Okubo K, Shimomura I, Mizuno K, Matsuzawa Y \& Matsubara K 1997 Analysis of an expression profile of genes in the human adipose tissue. Gene 190 227-235.

Matsuyama H, Ruhmann-Wennhold A \& Nelson DH 1971 Radioimmunoassay of plasma ACTH in intact rats. Endocrinology 88 692-695.

Moldow R \& Yalow RS 1978 Extrahypophysial distribution of corticotropin as a function of brain size. PNAS 75 994-998.

Nishida K, Adachi W, Shimizu-Matsumoto A, Kinoshita S, Mizuno K, Matsubara K \& Okubo K 1996 A gene expression profile of human corneal epithelium and the isolation of human keratin 12 cDNA. Investigative Ophthalmology and Visual Science 37 1800-1809.

Nishida K, Honma Y, Dota A, Kawasaki S, Adachi W, Nakamura T, Quantock AJ, Hosotani H, Yamamoto S, Okada M et al. 1997 Isolation and chromosomal localization of a cornea-specific human keratin 12 gene and detection of four mutations in Meesmann corneal epithelial dystrophy. American Fournal of Human Genetics 61 1268-1275.

Nishiki M, Murakami Y, Ozawa Y \& Kato Y 2001 Serum antibodies to human pituitary membrane antigens in patients with autoimmune lymphocytic hypophysitis and infundibuloneurohypophysitis. Clinical Endocrinology 54 327-333.

Okubo K, Hori N, Matoba R, Niiyama T, Fukushima A, Kojima Y \& Matsubara K 1992 Large scale cDNA sequencing for analysis of quantitative and qualitative aspects of gene expression. Nature Genetics 2 173-179.

Okubo K, Itoh K, Fukushima A, Yoshii J \& Matsubara K 1995 Monitoring cell physiology by expression profiles and discovering cell type-specific genes by compiled expression profiles. Genomics 30 178-186.

Okuda T, Mita S, Yamauchi S, Fukuta M, Nakano H, Sawada T \& Habuchi O 2000 Molecular cloning and characterization of GalNAc 4-sulfotransferase expressed in human pituitary gland. Fournal of Biological Chemistry 51 40605-40613.

Panter S, Thomson R, de Bruxelles G, Laver D, Trevaskis B \& Udvardi M 2000 Identification with proteomics of novel proteins associated with the peribacteroid membrane of soybean root nodules. Molecular Plant-Microbe Interactions 13 325-333.
Patten JL, Johns DR, Valle D, Eil C, Gruppuso PA, Steele G, Smallwood PM \& Levine MA 1990 Mutation in the gene encoding the stimulatory $\mathrm{G}$ protein of adenylate cyclase in Albright's hereditary osteodystrophy. New England Fournal of Medicine 322 1412-1419.

Phillips III JA, Hjelle BL, Seeburg PH \& Zachmann M 1981 Molecular basis for familial isolated growth hormone deficiency. PNAS 78 6372-6375.

Schwindinger WF, Francomano CA \& Levine MA 1992 Identification of a mutation in the gene encoding the alpha subunit of the stimulatory $\mathrm{G}$ protein of adenylyl cyclase in McCune-Albright syndrome. PNAS 89 5152-5156.

Shimizu-Matsumoto A, Adachi W, Mizuno K, Inazawa J, Nishida K, Kinoshita S, Matsubara K \& Okubo K 1997 An expression profile of genes in human retina and isolation of a complementary DNA for a novel rod photoreceptor protein. Investigative Ophthalmology and Visual Science $\mathbf{3 8}$ 2576-2585.

Tatsumi K, Hayashizaki Y, Hiraoka Y, Miyai K \& Matsubara K 1988 The structure of the human thyrotropin b-subunit gene. Gene 73 489-497.

Tatsumi K, Miyai K, Notomi T, Kaibe K, Amino N, Mizuno Y \& Kohno H 1992 Cretinism with combined hormone deficiency caused by a mutation in the PIT1 gene. Nature Genetics $\mathbf{1}$ $56-58$.

Venter JC, Adams MD, Myers EW, Li PW, Mural RJ, Sutton GG, Smith HO, Yandell M, Evans CA, Holt RA et al. 2001 The sequence of the human genome. Science 291 1304-1351.

Weinstein LS, Gejman PV, de Mazancourt P, American N \& Spiegel AM 1992 A heterozygous 4-bp deletion mutation in the Gs alpha gene (GNAS1) in a patient with Albright hereditary osteodystrophy. Genomics 13 1319-1321.

Yokoyama M, Nishi Y, Yoshii J, Okubo K \& Matsubara K 1996 Identification and cloning of neuroblastoma-specific and nerve tissue-specific genes through compiled expression profiles. DNA Research 3 311-320.

Received 23 October 2001 Accepted 19 November 2001 